\title{
Determination of Lanthanoids in Seawater by Inductively Coupled Plasma Mass Spectrometry after Pre-Concentration with a Chelating Resin Disk
}

\author{
Megumi Fukai, Yoshikazu Kikawada, Takao 0i \\ Faculty of Science and Technology, Sophia University, Tokyo, Japan \\ Email: t-ooi@sophia.ac.jp
}

How to cite this paper: Fukai, M., Kikawada, Y. and Oi, T. (2016) Determination of Lanthanoids in Seawater by Inductively Coupled Plasma Mass Spectrometry after PreConcentration with a Chelating Resin Disk. Natural Science, 8, 431-441.

http://dx.doi.org/10.4236/ns.2016.810045

Received: September 26, 2016

Accepted: October 24, 2016

Published: October 27, 2016

Copyright $\odot 2016$ by authors and Scientific Research Publishing Inc. This work is licensed under the Creative Commons Attribution International License (CC BY 4.0).

http://creativecommons.org/licenses/by/4.0/

\begin{abstract}
A seawater sample was analyzed for its lanthanoids (Ln's) contents by inductively coupled plasma mass spectrometry (ICP-MS). The analytical procedure included the pre-concentration and partial purification of Ln's with a chelating resin disk and the employment of the combination of the internal standard and standard addition methods in ICP-MS, which seemed indispensable for the determination of low-level Ln's by ICP-MS. The recoveries of the Ln's with the disk were mostly $70 \%$ or better with the concentration factor of 200. The measured concentrations of Ln's were on the order of $\mathrm{ng} \cdot \mathrm{dm}^{-3}$ or lower and reasonable except that of neodymium and samarium.
\end{abstract}

\section{Keywords}

Lanthanoids, Chelating Resin Disk, ICP-MS, Lanthanoid Abundance Pattern

\section{(c) (i) Open Access}

\section{Introduction}

Lanthanoids (Ln's; ${ }_{57} \mathrm{La}{ }_{71} \mathrm{Lu}$ ) are elements contained in high level radioactive wastes as fission products, and in addition, they are useful natural analogues for some transuranic (TRU) elements leaked into the natural environments [1]. Thus, Ln's have been and are used in studies on the geological disposal of radioactive wastes as analogues for TRU elements [2] [3]. Grasping the behaviors of Ln's in nature results in better understanding of those of TRU elements in nature. Ln's are also often used as tracers in studies on natural environments because of their similar but consecutively changing atomic and ionic properties and frequently observed anomalous behaviors of cerium (Ce) 
and europium $(\mathrm{Eu})$. Their concentrations in natural environments are, however, usually very low especially in aqueous environments. For instance, their concentrations in seawater are reported to be on the order of $\mathrm{ng} \cdot \mathrm{kg}^{-1}$ or lower [4]. Precise and reliable analytical techniques are thus indispensable. Previous investigations of Ln's have largely been based on determinations by isotope dilution thermal ionization mass spectrometry (ID-TIMS). This method is precise, but sample preparation is quite tedious and time consuming, and the largest drawback of the method is that it cannot be applied to mono-isotopic elements. In earlier studies, De Baar et al. [5]-[7] employed neutron activation analysis (NAA) for the determination of Ln's including the mono-isotopic ones. In our previous papers [8]-[10], we applied NAA to the determination of Ln's and thorium (Th) and uranium (U) in seawater- and brine-related substances. Unfortunately, the NAA method does not seem to be precise enough for a detailed analysis of geochemical behavior across the Ln's. Shabani et al. [11] developed a method based on inductively coupled plasma mass spectrometry (ICP-MS). Nowadays, ICP-MS and ICP atomic emission spectroscopy (ICP-AES) seem the most commonly used method for the determination of trace Ln's because of their capability of rapid multi-element detection over a wide concentration range with relatively low detection limits.

Although ICP-MS and ICP-AES are a powerful method for the determination of Ln's in seawater and its related substances, their application to the determination of Ln's at very low concentration level is limited because high salinity can cause matrix effects and the high concentration of barium $(\mathrm{Ba})$ relative to Ln's interferes the determinations of samarium (Sm) and $\mathrm{Eu}$ by forming their isobaric $\mathrm{BaO}^{+}$and $\mathrm{BaOH}^{+}$ions. Therefore, separation of matrix components and pre-concentration of Ln's are a prerequisite. A variety of pre-concentration techniques have been adopted, which include co-precipitation, ion exchange, liquid-liquid extraction and solid-phase extraction (SPE). Among them, SPE based on the column chromatographic technique seems to be most frequently used. Such solid sorbents as chelating resin [12] [13], chelating fiber [14] and carbon nanotubes [15] [16] have been used as column packing materials.

Chelating resin disks may be an alternative to chromatographic columns packed with a sorbent. For the determination of Ln's in seawater by ICP-MS, we successfully used a chelating resin disk for separation of matrix components and pre-concentration of Ln's. In this paper, we report the determination of Ln's in seawater by ICP-MS after pretreatment using a chelating resin disk, in which a combination of the internal standard method and the standard addition method is also included.

\section{Experimental}

\subsection{Chelating Resin Disk and Chemicals, and Equipment}

The chelating resin disk (CD) used was the $3 \mathrm{M}$ Company Empore ${ }^{\mathrm{TM}}$ Chelating extraction disk for environmental analysis with the diameter of $47 \mathrm{~mm}$ and with the iminodiacetic acid component as the functional group. It was immersed in $3 \mathrm{~mol} \cdot \mathrm{dm}^{-3} \mathrm{HNO}_{3}$ solution overnight prior to the application to separation of matrix components and pre-concentration of Ln's. Water with the specific resistance of $18.2 \mathrm{M} \Omega \cdot \mathrm{cm}$ or higher 
at $25^{\circ} \mathrm{C}$ (Milli-Q water) used throughout was produced with a Millipore water purification system. Stock standard solutions of Ln's and indium (In) used as the internal standard substance and multielement standard solutions were purchased from Wako Pure Chemical Industries, Ltd. Working standard solutions were prepared by appropriate dilution and mixing of the stock standard solutions and addition of nitric acid $\left(\mathrm{HNO}_{3}\right)$. All other chemicals used were of analytical grade or better. The seawater sample used was kindly donated by Nihonkaisui Co. Ltd. It was collected off the coast of Onahama, Fukushima, Japan in 2009, and used after sand filtration.

The ICP-MS instrument used was a Seiko Instrument Model SPQ9000 ICP mass spectrometer. The operating conditions are summarized in Table 1 . The value of $\mathrm{pH}$ of solutions was measured with a Horiba twin pH B-212 pH meter. The glass filtration apparatus used was a product of Toyo Roshi Kaisha Ltd.

\subsection{Preliminary Experiments}

In advance of treating actual seawater, we first checked the performance of the CD using a sample solution containing lanthanum (La), gadolinium $(\mathrm{Gd})$ and lutetium $(\mathrm{Lu})$. $\mathrm{La}, \mathrm{Gd}$ and $\mathrm{Lu}$ were intended to be the representatives of the light, middle and heavy Ln's, respectively. Since the Ln's are mainly dissolved in seawater as carbonate complexes like $\mathrm{LnCO}_{3}^{+}$except Ce which forms $\mathrm{Ce}(\mathrm{OH})_{4}$ in seawater [4], the sample solu-

Table 1. Operating conditions for ICP-MS.

\begin{tabular}{|c|c|c|c|}
\hline \multicolumn{3}{|c|}{$\mathrm{RF}$ power/kW } & 1.0 \\
\hline \multicolumn{3}{|c|}{ Plasma gas flow rate $/ \mathrm{dm}^{3} \cdot \mathrm{min}^{-1}$} & 16.0 \\
\hline \multicolumn{3}{|c|}{ Auxiliary gas flow rate $/ \mathrm{dm}^{3} \cdot \mathrm{min}^{-1}$} & 1.00 \\
\hline \multicolumn{3}{|c|}{ Nebulizer gas flow rate $/ \mathrm{dm}^{3} \cdot \mathrm{min}^{-1}$} & 1.00 \\
\hline \multicolumn{2}{|c|}{ Interface } & \multicolumn{2}{|c|}{ Copper } \\
\hline \multicolumn{2}{|c|}{ Nebulizer } & \multicolumn{2}{|c|}{ Concentric pneumatic type } \\
\hline \multicolumn{2}{|c|}{ Spray chamber } & \multicolumn{2}{|c|}{ Scot type } \\
\hline \multicolumn{3}{|c|}{ Dwell time/s } & 1 \\
\hline \multicolumn{3}{|c|}{ Number of replicates } & 5 \\
\hline \multicolumn{4}{|c|}{ Measured isotopes } \\
\hline Element & $\mathrm{m} / \mathrm{z}$ & Element & $\mathrm{m} / \mathrm{z}$ \\
\hline $\mathrm{La}$ & 139 & Dy & 164 \\
\hline $\mathrm{Ce}$ & 140 & Ho & 165 \\
\hline $\operatorname{Pr}$ & 141 & Er & 166 \\
\hline $\mathrm{Nd}$ & $142^{\mathrm{a}}$ & $\operatorname{Tm}$ & 169 \\
\hline Sm & 152 & $\mathrm{Yb}$ & 174 \\
\hline $\mathrm{Eu}$ & 153 & $\mathrm{Lu}$ & 175 \\
\hline Gd & 158 & In & 115 \\
\hline $\mathrm{Tb}$ & 159 & & \\
\hline
\end{tabular}

${ }^{\text {a. }}{ }^{142} \mathrm{Ce}$ interference was corrected with the ratio of ${ }^{142} \mathrm{Ce} /{ }^{140} \mathrm{Ce}$. 
tion for the preliminary experiments was prepared from $1 \mathrm{dm}^{3}$ of $0.1 \mathrm{~mol} \cdot \mathrm{dm}^{-3}$ sodium hydrogen carbonate $\left(\mathrm{NaHCO}_{3}\right)$ solution according to the pre-treatment procedures for separation of matrix components and pre-concentration of Ln's in aqueous solutions with the $\mathrm{CD}$ [17]. The preparation procedure of the sample solution was as follows. The $\mathrm{pH}$ of the $0.1 \mathrm{~mol} \cdot \mathrm{dm}^{-3} \mathrm{NaHCO}_{3}$ solution was first adjusted to $<2$ with $\mathrm{HNO}_{3} .5 \mathrm{~mol}$. $\mathrm{dm}^{-3}$ ammonium acetate $\left(\mathrm{CH}_{3} \mathrm{COONH}_{4}\right)$ solution was then added to this $\mathrm{pH}$-adjusted solution so that the concentration of $\mathrm{CH}_{3} \mathrm{COONH}_{4}$ became $0.1 \mathrm{~mol} \cdot \mathrm{dm}^{-3}$, and the $\mathrm{pH}$ of the resultant solution was adjusted to 5 with $\mathrm{HNO}_{3}$ and ammonia water $\left(\mathrm{NH}_{4} \mathrm{OH}\right)$. Finally, a solution containing $\mathrm{La}, \mathrm{Gd}$ and $\mathrm{Lu}$ was added to this solution to obtain the sample solution for the preliminary experiments. The contents of La, Gd and Lu in the sample solution were $49.5 \mathrm{ng}, 50.0 \mathrm{ng}$ and $49.5 \mathrm{ng}$, respectively.

The conditioning of the CD was carried out by referring to that of Maruta et al. [17] and Takaku et al. [18]. After set on a filter holder of the filtration equipment, the CD was wetted with $20 \mathrm{~cm}^{3}$ of Milli-Q water, washed with $20 \mathrm{~cm}^{3}$ of $3 \mathrm{~mol} \cdot \mathrm{dm}^{-3} \mathrm{HNO}_{3}$ and finally washed with $50 \mathrm{~cm}^{3}$ of Milli-Q water twice under suction. The chemical form of its functional group was then changed to the ammonium $\left(\mathrm{NH}_{4}^{+}\right)$form with $50 \mathrm{~cm}^{3}$ of $0.1 \mathrm{~mol} \cdot \mathrm{dm}^{-3} \mathrm{CH}_{3} \mathrm{COONH}_{4}$, and the $\mathrm{CD}$ in the $\mathrm{NH}_{4}^{+}$form was washed with a small amount of Milli-Q water. The CD thus conditioned was ready for use.

The whole volume of the above mentioned sample solution for the preliminary experiments was passed through the conditioned $\mathrm{CD}$. After the $\mathrm{CD}$ was washed with 100 $\mathrm{cm}^{3}$ of $0.25 \mathrm{~mol} \cdot \mathrm{dm}^{-3} \mathrm{CH}_{3} \mathrm{COONH}_{4}$ solution, the Ln's ( $\mathrm{La}, \mathrm{Gd}, \mathrm{Lu}$ ) adsorbed on the CD was eluted out with $35 \mathrm{~cm}^{3}$ of $2 \mathrm{~mol} \cdot \mathrm{dm}^{-3} \mathrm{HNO}_{3}$ solution. The effluent containing the Ln's was evaporated to dryness on a hot plate, and the evaporation residue was dissolved with $\mathrm{HNO}_{3}$ solution. The volume of the solution was adjusted to $50 \mathrm{~cm}^{3}$ after $5.00 \mathrm{~cm}^{3}$ of an aqueous solution containing $100 \mu \mathrm{g} \cdot \mathrm{dm}^{-3}$ In used as the internal standard and $2 \mathrm{~mol} \cdot \mathrm{dm}^{-3} \mathrm{HNO}_{3}$ solution, whose volume was determined so that the final $\mathrm{HNO}_{3}$ concentration became $0.9 \mathrm{~mol} \cdot \mathrm{dm}^{-3}$, were added. The solution prepared in this way was subjected to the ICP-MS. The concentration factor was thus 20 .

\subsection{Determination of Concentrations of Ln's in Seawater}

\subsubsection{Determination by the Internal Standard Method after Pre-Concentration with the CD}

The procedure for pre-treatment with $\mathrm{CD}$ was similar to that adopted in the preliminary experiments. The $\mathrm{pH}$ of the $4 \mathrm{dm}^{3}$ aliquot of the seawater sample was first adjusted to $<2$. After its $\mathrm{CH}_{3} \mathrm{COONH}_{4}$ concentration was adjusted to $0.1 \mathrm{~mol} \cdot \mathrm{dm}^{-3}$ by adding an appropriate volume of the $5 \mathrm{~mol} \cdot \mathrm{dm}^{-3} \mathrm{CH}_{3} \mathrm{COONH}_{4}$ solution, the $\mathrm{pH}$ was adjusted to 5 with $\mathrm{HNO}_{3}$ or $\mathrm{NH}_{4} \mathrm{OH}$. The $\mathrm{pH}$ - and $\mathrm{CH}_{3} \mathrm{COONH}_{4}$ concentration-adjusted aliquot was passed through the $\mathrm{CD}$. After the $\mathrm{CD}$ was washed with $100 \mathrm{~cm}^{3}$ of $0.25 \mathrm{~mol} \cdot \mathrm{dm}^{-3}$ $\mathrm{CH}_{3} \mathrm{COONH}_{4}$ solution for the removal of alkali earth metals [18], Ln's adsorbed on the $\mathrm{CD}$ was eluted out with $35 \mathrm{~cm}^{3}$ of $2 \mathrm{~mol} \cdot \mathrm{dm}^{-3} \mathrm{HNO}_{3}$ solution. The effluent containing Ln's was evaporated to dryness on the hot plate, and the evaporation residue was dissolved with $\mathrm{HNO}_{3}$ solution. The volume of the solution was adjusted to $20 \mathrm{~cm}^{3}$ after $2.00 \mathrm{~cm}^{3}$ of $100 \mu \mathrm{g} \cdot \mathrm{dm}^{-3} \mathrm{In}$ solution and a certain volume of $2 \mathrm{~mol} \cdot \mathrm{dm}^{-3} \mathrm{HNO}_{3}$ solution 
were added. The final solution whose $\mathrm{HNO}_{3}$ concentration was $0.6 \mathrm{~mol} \cdot \mathrm{dm}^{-3}$ was subjected to the ICP-MS. The concentration factor in this case was 200 . The concentrations of Ln's in the final solution were calculated by the standard curve method incorporating the internal standard method using In as the internal standard. The standard curve for a Ln was obtained from the ratios of the counting rates of the Ln to those of In in the standard solutions, and the concentration of the $\mathrm{Ln}$ in the final solution, $c_{\mathrm{Ln}}$, was calculated by interpolation on the curve. The concentration of the $\mathrm{Ln}$ in the seawater sample, $\mathcal{c}_{\mathrm{Ln}, \mathrm{A}}$, in $\mathrm{ng} \cdot \mathrm{dm}^{-3}$ is then given as Equation (1),

$$
c_{\mathrm{Ln}, \mathrm{A}}=\frac{C_{\mathrm{Ln}}}{200}
$$

The analytical procedure in this subsection is hereafter referred to as Procedure A.

\subsubsection{Determination by Combination of Internal Standard and Standard Addition Methods after Pre-Concentration with the CD}

The concentrations of Ln's in the seawater sample were also determined using the combination of the internal standard and standard addition methods. This analytical procedure is hereafter referred to as Procedure B. The concentration of a Ln determined by Procedure B should be equal to that determined by Procedure A within experimental uncertainties if the $\mathrm{Ln}$ is completely trapped on the $\mathrm{CD}$ in the pre-concentration treatment.

Known amounts of Ln's were added to a $4 \mathrm{dm}^{3}$ aliquot of the seawater sample. Those amounts were determined based on the analytical results obtained by Procedure A and are listed in Table 2. The Ln's-added aliquot was subjected to the same treatment as the one in the previous subsection and the concentrations of Ln's were determined by the internal standard technique. Assuming that the recoveries of a Ln from the aliquot and the Ln's-added aliquot are the same in the pre-concentration process, the concentration of a $\mathrm{Ln}, \mathcal{c}_{\mathrm{Ln}, \mathrm{B}}$, in $\mathrm{ng} \cdot \mathrm{dm}^{-3}$ in the seawater sample was obtained by Procedure B as Equation (2),

$$
c_{\mathrm{Ln}, \mathrm{B}}=c_{\mathrm{Ln}, \mathrm{A}} \times \frac{m_{\mathrm{Ln}}}{c_{\mathrm{Ln} \text { (added) }} \times 0.020-c_{\mathrm{Ln}, \mathrm{A}} \times 4}
$$

where $m_{\mathrm{Ln}}$ is the amount of the added Ln in ng and $c_{\mathrm{Ln} \text { (added) }}$ is the concentration of the $\mathrm{Ln}$ in $\mathrm{ng} \cdot \mathrm{dm}^{-3}$ in the final solution of the Ln's-added seawater sample.

\section{Results and Discussion}

\subsection{Preliminary Experiments}

Three similar experiments were conducted. The mean recovery was $107 \% \pm 8 \%, 105 \%$ $\pm 7 \%$ and $96 \% \pm 1 \%$ ( \pm representing the $1 \sigma$ ) for $\mathrm{La}, \mathrm{Gd}$ and $\mathrm{Lu}$, respectively. This result shows that the $\mathrm{CD}$ trapped the Ln's completely and they were completely eluted out with $2 \mathrm{~mol} \cdot \mathrm{dm}^{-3} \mathrm{HNO}_{3}$ solution after surviving the wash with $0.25 \mathrm{~mol} \cdot \mathrm{dm}^{-3} \mathrm{CH}_{3} \mathrm{COONH}_{4}$ solution within experimental uncertainties. 
Table 2. Amounts of Ln's added to $4 \mathrm{dm}^{3}$ of seawater sample in standard addition method.

\begin{tabular}{cc}
\hline Element & Amount of added Ln/ng \\
\hline La & 4.21 \\
$\mathrm{Ce}$ & 6.61 \\
$\mathrm{Pr}$ & 0.97 \\
$\mathrm{Nd}$ & 4.80 \\
$\mathrm{Sm}$ & 2.16 \\
$\mathrm{Eu}$ & 0.56 \\
$\mathrm{Gd}$ & 3.66 \\
$\mathrm{~Tb}$ & 0.61 \\
$\mathrm{Dy}$ & 3.27 \\
$\mathrm{Ho}$ & 1.10 \\
$\mathrm{Er}$ & 3.24 \\
$\mathrm{Tm}$ & 0.73 \\
$\mathrm{Yb}$ & 3.38 \\
$\mathrm{Lu}$ & 0.58 \\
\hline
\end{tabular}

\subsection{Concentrations of Ln's in Seawater}

The analytical results are summarized in Table 3. Ln's on the order of ng. $\mathrm{dm}^{-3}$ were found both by Procedures A and B. The standard deviations in Procedure B appear to be higher than those in Procedure A due to propagation of errors of $c_{\mathrm{Ln}, \mathrm{A}}, c_{\mathrm{Ln} \text { (added) }}$ and $m_{\mathrm{Ln}}$. Procedure $\mathrm{B}$ yielded a higher concentration for every $\mathrm{Ln}$ except $\mathrm{Eu}$ and $\mathrm{Tb}$ than Procedure A, which strongly indicates that the CD adsorbed only a part of dissolved Ln. Although the preliminary experiments showed that the CD did adsorb all the amounts of the Ln's in the sample solution, it is different from seawater in many ways. Seawater contains practically all naturally occurring elements, and the procedure using the $\mathrm{CD}$ can capture most multivalent metal ions except alkali earth metals. Although the decreasing order of the selectivity for trivalent ions on the imminodiacetic acid resin is reported as $\mathrm{Fe}^{3+}>\mathrm{La}^{3+}>\mathrm{Al}^{3+}[19]$, many of divalent and trivalent metal ions are higher in concentration in seawater than Ln's. It is thus reasonable that the CD could take up only a part of a Ln dissolved in $4 \mathrm{dm}^{3}$ of the seawater sample. Consequently, the analytical results by Procedure B are considered to be more reliable than those by Procedure A.

In the standard addition method, the amount of the element to be added to the sample is important. In this study, the amounts of Ln's added to the seawater sample in Procedure B were determined based on the results by Procedure A; that is, they mimicked those estimated from the concentrations in the seawater sample determined by Procedure A.

The recovery of a $\mathrm{Ln}$ in $\%, r_{\mathrm{Ln}}$, from seawater with the $\mathrm{CD}$ is calculable by Equation (3) and the results are summarized in Table 4. 


$$
r_{\mathrm{Ln}}=\frac{c_{\mathrm{Ln}, \mathrm{A}}}{c_{\mathrm{Ln}, \mathrm{B}}} \times 100=\frac{c_{\mathrm{Ln}(\text { added) }} \times 0.020-c_{\mathrm{Ln}, \mathrm{A}} \times 4}{m_{\mathrm{Ln}}} \times 100
$$

It varies between $41 \%$ to $100 \%$ with the simple arithmetic average of $76 \%$. The recovery of neodymium $(\mathrm{Nd})$ and $\mathrm{Sm}$ seems somewhat too low. The average is $81 \%$ if the $\mathrm{Nd}$ and $\mathrm{Sm}$ data are omitted.

Table 3. Concentrations of Ln's in seawater.

\begin{tabular}{ccccc}
\hline & & \multicolumn{2}{c}{ Concentration $/ \mathrm{ng}^{2} \mathrm{dm}^{-3}$} & \\
\cline { 2 - 5 } Element & Procedure A & $\mathrm{SD}^{\mathrm{a}}$ & Procedure B & $\mathrm{SD}^{\mathrm{a}}$ \\
\hline $\mathrm{La}$ & 4.7 & 0.11 & 7.4 & 3.0 \\
$\mathrm{Ce}$ & 3.6 & 0.10 & 4.7 & 0.2 \\
$\mathrm{Pr}$ & 0.8 & 0.04 & 0.9 & 2.9 \\
$\mathrm{Nd}$ & 3.4 & 0.15 & 7.9 & 1.5 \\
$\mathrm{Sm}$ & 1.7 & 0.06 & 4.1 & \\
$\mathrm{Eu}$ & 0.4 & 0.02 & 0.4 & 1.6 \\
$\mathrm{Gd}$ & 2.1 & 0.17 & 3.2 & \\
$\mathrm{~Tb}$ & 0.4 & 0.02 & 0.4 & 0.5 \\
$\mathrm{Dy}$ & 2.0 & 0.04 & 2.4 & 0.2 \\
$\mathrm{Ho}$ & 0.5 & 0.02 & 0.5 & 0.4 \\
$\mathrm{Er}$ & 1.9 & 0.05 & 2.3 & 0.1 \\
$\mathrm{Tm}$ & 0.3 & 0.01 & 0.4 & 0.6 \\
$\mathrm{Yb}$ & 1.6 & 0.06 & 2.3 & 0.1 \\
$\mathrm{Lu}$ & 0.3 & 0.01 & 0.4 &
\end{tabular}

a: Standard deviation (5 measurements).

Table 4. Recoveries of Ln's from seawater with CD.

\begin{tabular}{ll}
\hline Element & Recovery/\% \\
\hline La & 63 \\
Ce & 75 \\
Pr & 86 \\
Nd & 43 \\
Sm & 41 \\
Eu & 100 \\
Gd & 66 \\
Tb & 100 \\
Dy & 83 \\
Ho & 95 \\
Er & 83 \\
Tm & 77 \\
Yb & 71 \\
Lu & 75 \\
\hline
\end{tabular}




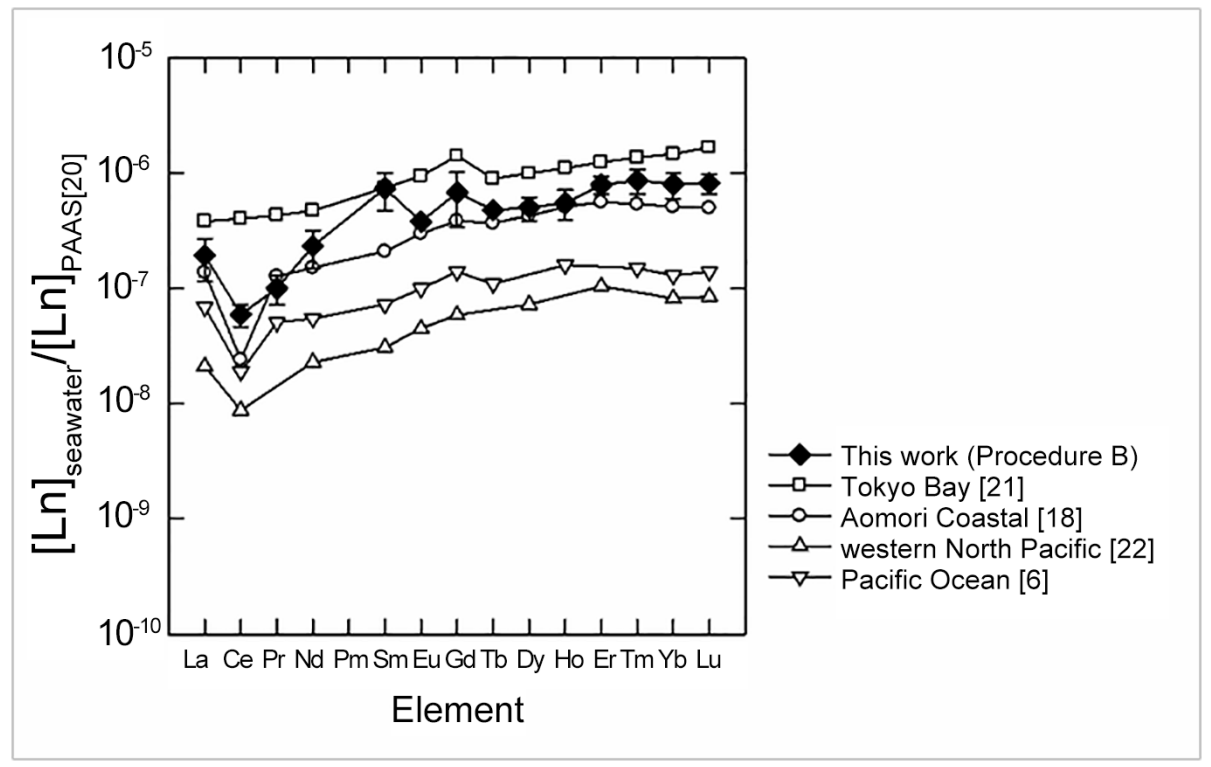

Figure 1. PAAS-normalized patterns of Ln's in seawater.

Since there are no certified values of the concentrations of the Ln's in the present seawater sample, the actual reliability of the data obtained by Procedure B is unknown. One way to check it may be to draw the Ln abundance pattern and compared it with those found in literature. The Ln abundance pattern obtained by normalization with the contents of the Ln's in post-Archean average Australian shale (PAAS) [20] is shown in Figure 1 together with those by some other researchers [6] [18] [21] [22]. Our pattern is similar to the others as a whole. The negative Ce and positive $\mathrm{Gd}$ anomalies observed in our pattern seem to be reasonable. The negative Ce anomaly is commonly found in Ln abundance patterns of seawater due to the preferential scavenging of $\mathrm{Ce}(\mathrm{IV})$ with suspended matters like hydrous iron oxides. The determinant of the Gd anomaly in Ln abundance patterns of seawater is rather complicated. In the present case, it might be caused by the presence of anthropogenic organic complexes of Gd like Gd-DTPA used for a medical diagnosis, since the seawater sample used in this study was collected near the shore with moderate human activity. Such anthropogenic Gd anomalies in river waters and coastal seawaters were reported in several literatures [21] [23]-[25]. The alternative possible cause of the Gd anomaly is the differences in complexation behavior between Gd and its neighbors, Eu and Tb, in seawaters [6] [7]. Compared to the other determined Ln's, $\mathrm{Nd}$ and $\mathrm{Sm}$ are obviously overestimated in our experiments, which must reflect the too low recoveries of $\mathrm{Nd}$ and $\mathrm{Sm}$.

\section{Conclusions}

To summarize the present study, we make the following statements.

The chelating resin disk ( $3 \mathrm{M}$ Empore ${ }^{\mathrm{TM}}$ chelating resin disk) is effective for the concentration of Ln's from seawater. At the concentration factor of 200, the recovery of the Ln's with the disk was $70 \%$ or better for the majority of the Ln's. 
In analyzing Ln's in seawater by ICP-MS, the combination of the internal standard and standard addition methods was adopted. As a result, Ln's on the order of $\mathrm{ng}^{-\mathrm{dm}^{-3}}$ were found, which seems reasonable by the comparison with similar data in literature. The $\mathrm{Ln}$ abundance pattern shows the positive Sm and Gd anomalies and the negative Ce anomaly. Among them, the Sm anomaly is probably a fake ascribable to its too low recovery in the pre-concentration process with the chelating disk. Thus, a further optimization of the conditions for the pre-concentration of the Ln's with the chelating disk is required. The incorporation of the standard addition method is indispensable to determine the concentration of Ln's in seawater.

\section{References}

[1] Krauskopf, K.B. (2008) Thorium and Rare-Earth Metals as Analogs for Actinide Elements. Chemical Geology, 55, 323-335. http://dx.doi.org/10.1016/0009-2541(86)90033-1

[2] Lee, S.G., Lee, K.Y., Cho, S.Y., Yoon, Y.Y. and Kim, Y. (2006) Sorption Properties of ${ }^{152} \mathrm{Eu}$ and ${ }^{241} \mathrm{Am}$ in Geological Materials: Eu as an Analogue for Monitoring the Am Behaviour in Heterogeneous Geological Environments. Geoscience Journal, 10, 103-114.

http://dx.doi.org/10.1007/BF02910354

[3] Dobashi, R. and Shikazono, N. (2008) Geochemical Study of Rare Earth Elements in Carbonate Minerals in Sedimentary Rocks around Tono Uranium Deposit, Central Japan: An Example of Natural Analogue Study of Geological Disposal of High-Level Nuclear Waste. Chikyukagaku (Geochemistry), 42, 79-98.

[4] Nozaki, Y. (1997) Updated (1996 Version) Table of Elements in Seawater and Its Remarks. Bulletin of the Society of Sea Water Science, Japan, 51, 302-308.

[5] De Baar, H.J.W., Bacon, M.P. and Brewer, P.G. (1983) Rare-Earth Distributions with a Positive Ce Anomaly in the Western North Atlantic Ocean. Nature, 301, 324-327. http://dx.doi.org/10.1038/301324a0

[6] De Baar, H.J., Bacon, M.P., Brewer, P.G. and Bruland, K.W. (1985) Rare Earth Elements in the Pacific and Atlantic Oceans. Geochimica et Cosmochimica Acta, 49, 1943-1959. http://dx.doi.org/10.1016/0016-7037(85)90089-4

[7] De Baar, H.J., Brewer, P.G. and Bacon, M.P. (1985) Anomalies in Rare Earth Distributions in Seawater: Gd and Tb. Geochimica et Cosmochimica Acta, 49, 1961-1969. http://dx.doi.org/10.1016/0016-7037(85)90090-0

[8] Yui, M., Kikawada, Y., Oi, T., Honda, T. and Nozaki, T. (1998) Abundance of Lanthanoids in Rock Salts Determined by Neutron Activation Analysis. Journal of Radioanalytical and Nuclear Chemistry, 238, 3-6. http://dx.doi.org/10.1007/BF02385347

[9] Yui, M., Kikawada, Y., Oi, T., Honda, T. and Nozaki, T. (1998) Abundance of Uranium and Thorium in Rock Salts. Partition of Uranium and Thorium between Solid and Solution Phases in Neutral Environments in Nature. Radioisotopes, 47, 488-492. http://dx.doi.org/10.3769/radioisotopes.47.488

[10] Yui, M., Kikawada, Y., Oi, T., Honda, T., Sun, D., and Shuai, K. (1998) A Preliminary Investigation on the Determination of Lanthanoids, Thorium and Uranium in Brine and Deposit of a Salt Lake in China. Journal of Radioanalytical and Nuclear Chemistry, 231, 83-86. http://dx.doi.org/10.1007/BF02388010

[11] Shabani, M.B., Akagi, T., Shimizu, H. and Masuda, A. (1990) Determination of Trace Lanthanides and Yttrium in Seawater by Inductively Coupled Plasma Mass Spectrometry after Preconcentration with Solvent Extraction and Back-Extraction. Analytical Chemistry, 62, 
2709-2714. http://dx.doi.org/10.1021/ac00223a012

[12] Rahmi, D., Zhu, Y., Fujimori, E., Umemura, T. and Haraguchi, H. (2007) Multielement Determination of Trace Metals in Seawater by ICP-MS with Aid of Down-Sized Chelating Resin-Packed Minicolumn for Preconcentration. Talanta, 72, 600-606.

http://dx.doi.org/10.1016/j.talanta.2006.11.023

[13] Kim, I., Kim, S. and Kim, G. (2010) Analytical Artifacts Associated with the Chelating Resin Extraction of Dissolved Rare Earth Elements in Natural Water Samples. Aquatic Geochemistry, 16, 611-620. http://dx.doi.org/10.1007/s10498-010-9100-5

[14] Zhang, T.H., Shan, X.Q., Liu, R.X., Tang, H.X. and Zhang, S.Z. (1998) Preconcentration of Rare Earth Elements in Seawater with Poly (Acrylaminophosphonic Dithiocarbamate) Chelating Fiber Prior to Determination by Inductively Coupled Plasma Mass Spectrometry. Analytical Chemistry, 70, 3964-3968. http://dx.doi.org/10.1021/ac980321h

[15] Liang, P., Liu, Y. and Guo, L. (2005) Determination of Trace Rare Earth Elements by Inductively Coupled Plasma Atomic Emission Spectrometry after Preconcentration with Multiwalled Carbon Nanotubes. Spectrochimica Acta Part B, 60, 125-129.

http://dx.doi.org/10.1016/j.sab.2004.11.010

[16] Cho, J., Chung, K.W., Choi, M.S. and Kim, H.J. (2012) Analysis of Rare Earth Elements in Seawater by Inductively Coupled Plasma Mass Spectrometry after Pre-Concentration Using TSK $^{\mathrm{mm}}$-HD-MW-CNTs (Highly Dispersive Multi-Walled Carbon Nanotubes). Talanta, 99, 369-374. http://dx.doi.org/10.1016/j.talanta.2012.05.066

[17] Maruta, F., Kato, K. and Tonouchi, S. (2003) Study on Determination of Uranium and Rare Earth Elements in Seawater and Riverwater by ICP-MS with Chelating Resin Disk Pretreatment. Annual Report of Nigata Prefectural Institute of Environmental radiation Monitoring, 1, 45-49.

[18] Takaku, Y., Kudo, Y., Kimura, J., Hayashi, T., Ota, I., Hasegawa, H. and Ueda, S. (2002) Determination of Rare-Earth Elements on Environmental Water Using Chelating Resin Disk Separation/ICP-MS. Bunseki Kagaku (Analytical Chemistry), 51, 539-544. http://dx.doi.org/10.2116/bunsekikagaku.51.539

[19] Yuchi, A., Sato, T., Morimoto, Y., Mizuno, H. and Wada, H. (1997) Adsorption Mechanism of Trivalent Metal Ions on Chelating Resins Containing Iminodiacetic Acid Groups with Reference to Selectivity. Analytical Chemistry, 69, 2941-2944. http://dx.doi.org/10.1021/ac9612685

[20] Nozaki, Y. and Alibo, D.S. (2003) Dissolved Rare Earth Elements in the Southern Ocean, Southwest of Australia: Unique Patterns Compared to the South Atlantic Data. Geochemical Journal, 37, 47-62. http://dx.doi.org/10.2343/geochemj.37.47

[21] Nozaki, Y., Lerche, D., Alibo, D.S. and Tsutsumi, M. (2000) Dissolved Indium and Rare Earth Elements in Three Japanese Rivers and Tokyo Bay: Evidence for Anthropogenic Gd and In. Geochimica et Cosmochimica Acta, 64, 3975-3982.

http://dx.doi.org/10.1016/s0016-7037(00)00472-5

[22] Piepgras, D.J. and Jacobsen, S.B. (1992) The Behavior of Rare Earth Elements in Seawater: Precise Determination of Variations in the North Pacific Water Column. Geochimica et Cosmochimica Acta, 56, 1851-1862. http://dx.doi.org/10.1016/0016-7037(92)90315-A

[23] Bau, M. and Dulski, P. (1996) Anthropogenic Origin of Positive Gadolinium Anomalies in River Waters. Earth and Planetary Science Letters, 143, 245-255. http://dx.doi.org/10.1016/0012-821X(96)00127-6

[24] Zhu, Y., Hoshino, M., Yamada, H., Itoh, A. and Haraguchi, H. (2004) Gadolinium Anomaly in the Distributions of Rare Earth Elements Observed for Coastal Seawater and River Wa- 
ters around Nagoya City. Bulletin of the Chemical Society of Japan, 77, 1835-1842. http://dx.doi.org/10.1246/bcsj.77.1835

[25] Kulaksız, S. and Bau, M. (2007) Contrasting Behaviour of Anthropogenic Gadolinium and Natural Rare Earth Elements in Estuaries and the Gadolinium Input into the North Sea. Earth and Planetary Science Letters, 260, 361-371.

http://dx.doi.org/10.1016/j.epsl.2007.06.016

Submit or recommend next manuscript to SCIRP and we will provide best service for you:

Accepting pre-submission inquiries through Email, Facebook, LinkedIn, Twitter, etc. A wide selection of journals (inclusive of 9 subjects, more than 200 journals)

Providing 24-hour high-quality service

User-friendly online submission system

Fair and swift peer-review system

Efficient typesetting and proofreading procedure

Display of the result of downloads and visits, as well as the number of cited articles Maximum dissemination of your research work

Submit your manuscript at: http://papersubmission.scirp.org/

Or contact ns@scirp.org 